\title{
Correlation between the bacterial community and flavour of fermented fish
}

\author{
Jin-Le Wang ${ }^{1,2 \#}$, Feng Zhao ${ }^{1,2 \#}$, Zuo-Ma Cairang ${ }^{1,2}$, Xiao-Yi Li ${ }^{1,2}$, Jie Kong ${ }^{1,2}$, Shi-Yu Zeng ${ }^{1,2}$, Mei-Yan Zhang ${ }^{1,2}$, \\ Zhen-Xin Zhao ${ }^{1,2}$, Xiao-Ping Zhang ${ }^{1,2}$ * \\ ${ }^{1}$ Institute of Fisheries, Guizhou Academy of Agricultural Sciences, Guiyang, Guizhou Province, China; ${ }^{2}$ Guizhou Special \\ Aquatic Products Engineering Technology Center, Guiyang, Guizhou Province, China
}

\#Joint first authors: The authors contributed equally to this work.

*Corresponding author: Xiao-Ping Zhang, Institute of Fisheries, Guizhou Academy of Agricultural Sciences, No. 2448, South Huaxi Avenue, Huaxi District, Guiyang, Guizhou Province, China. Email: 124362360@qq.com

Received: 23 March 2021; Accepted: 6 August 2021; Published: 13 October 2021

(C) 2021 Codon Publications

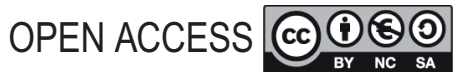

RESEARCH ARTICLE

\begin{abstract}
Common carp is a fish species of economic importance in China;traditionally it is mostly salt-fermented. In the fermenting process, the bacterial community of spontaneously fermented fish is important for its flavour and quality. However, very few studies have been conducted about the relationship between bacterial community and development of flavour involved in the salt-fermentation of carp. Therefore, we explored this relationship by determining the flavour components, including amino acids, and changes in volatile flavour and bacterial metabolite. Samples were taken during fermentation on the days $0,10,20,30,40$ and 50 . The second-generation $16 \mathrm{~S}$ recombinant DNA (rDNA) sequencing was performed to analyze the composition of bacteria. Contents of amino acids were determined by reverse-phase high-performance liquid chromatography combined with ultraviolet detection. The volatile components were analyzed with solid-phase microextraction-gas chromatography-mass spectrometry. Enterococcus, Lactobacillus, Lactococcus, Leuconostoc, and Staphylococcus were the dominant bacteria. The bidirectional orthogonal partial least squares approach was used to analyze the correlation between bacterial succession and flavour component dynamics. This study would help to better understand the role of bacteria in the fermented fish meat flavour and support the industrial production of fermented fish.
\end{abstract}

Keywords: fermented fish; bacterial community; flavour

\section{Introduction}

Fresh fish is one of the most highly perishable foods; its quality deteriorates rapidly during storage and handling, which severely limits the shelf-life of the product (Sallam. 2007). For this reason, there are many traditional methods of fish preservation, including salt-fermentation (Jung et al., 2013). Fermented fish is generally prepared by spontaneous (approximately) 1-month fermentation of salted whole or sectioned fish (Ji et al., 2017). Fermented fish contains proteins, carbohydrates, free amino acids, and a relatively low content of fat and biogenic amines (Wang et al., 2014). During the fermentation process, the fermented fish gains favourable flavour and extended shelf-life due to the co-functioning of complex bacterial communities (Dai et al., 2013). The salt-fermentation of fish is one of the oldest traditional preservation methods and it has remained in use in many parts of the world. Similar low-salt fermented fish products are widely produced and consumed in Japan, Southeast Asia, and Africa (Kouakou et al., 2012; Marui et al., 2014; Paludan-Müller et al., 2002; Takahashi and Kimura, 2010).

Traditional solid-state fermented fish is naturally fermented by a complex microbial activity (Zeng et al., 2013). In fermented foods, the types of microorganisms 
involved in the fermentation process often play a crucial role in the safety, texture, colour, and flavour of product (Stergaard et al., 1998). The metabolism of microbiota determines the composition and content of flavour-producing substances (Wolfe and Dutton, 2015; Wolfe et al., 2014), and the composition of the microbiota is affected by environmental conditions (De Filippis et al., 2015). Recently, the microbial community of traditional sour fish was analysed by the metagenomic analysis method (Yu et al., 2017), and the results showed that Lactobacillus was the dominant bacteria (Riquelme et al., 2015). However, studies conducted on fermented fish have not been reported yet. As unstable quality of flavour is the major problem in production of traditional fermented fish and modern industrial processing, understanding the structure of microbial community in fermented fish is a key for regulating and improving the quality of product.

Both microorganisms and endogenous enzymes promote the release of free fatty acids (FFA) in fermented fish, while microorganisms play a leading role in the production of flavour by various chemical reactions (Xu et al., 2018). However, the mechanism of flavour formation during fermentation has not been understood completely, and more research is required to record the relationship between microbial community, flavour, and flavour precursors. Many studies have successfully studied the correlation between bacterial composition and flavour compounds (Pang et al., 2018; Wang et al., 2016; Zheng et al., 2018). However, little research has been conducted on the relationship between bacterial succession and the volatile flavour components in fermented fish. In this study, free amino acids (FAAs), volatile flavour compounds, and microbial communities were analysed as fermentation progressed. The relationship between bacterial succession and the volatile flavour was analysed using the multivariate statistical analyses method, that is the bidirectional orthogonal partial least squares (O2PLS). These results would help to explore the core microbiota and flavour metabolites, and provide a technical reference for researchers in this field.

\section{Materials and Methods}

\section{Study design and sampling}

Alive common carp $(\mathrm{n}=140)$ with an average weight of 0.5 $\pm 0.3 \mathrm{~kg}$ were obtained from Guizhou Yuhe Agricultural Products Co. Ltd (Guiyang, Guizhou, China) and killed according to the Guidelines for the Treatment of Animals and Experimental Animal Management Regulations issued by the Ministry of Science and Technology of the People's Republic of China. The fermented fish meat was prepared in accordance with the traditional method prescribed by the residents of Qiandongnan Prefecture
(Guizhou, China), with minor modifications. Briefly, the fish meat was pickled with $3 \%(\mathrm{w} / \mathrm{w})$ standard kitchen salt at $4{ }^{\circ} \mathrm{C}$ for $48 \mathrm{~h}$ and dried for $3 \mathrm{~h}$ at $50^{\circ} \mathrm{C}$. After that, the fish meat was mixed with $30 \%(\mathrm{w} / \mathrm{w})$ of fermented glutinous rice (Yonghui Supermarket, Guiyang, China) manually. After that, the prepared mixture was placed in 10-L oxygen-free jars (Farmer's market, Jinping, Guizhou, China) and fermented at ambient temperature $\left(25^{\circ} \mathrm{C}\right)$ for 50 days. Three samples of fresh fish were taken (control) after pickled (0th), and on 10th, 20th, 30th, 40th and 50th day after fermentation; the samples taken on these time points were named CX, CTA, CTB, CTC, CTD, CTE, and CTF, respectively. All muscle samples were stored at $-80^{\circ} \mathrm{C}$ for further analyses (conducted within 3 weeks).

\section{Processing of sequence and community structure data}

De-multiplexed and quality-filtered raw reads were analyzed using QIIME software (v.1.9.1). The representative operational taxonomic units (OTU) sequences were annotated using the database of QIIME-based wrapper of Ribosomal Database Project (RDP) classifier (v.2.2) (Wang et al., 2007). Alpha diversity was calculated using the Hellinger distance between samples to reflect community diversity and richness. The relationships between samples were visualized according to principal component analysis (PCA) plots, which were calculated from the resulting distance matrices to compress dimensionality (Wang, 2012). Sequences of $97 \%$ identity were resolved at the species level (Ercolini et al., 2012; Koyanagi, 2011). The representative sequences of all OTUs were uploaded to GenBank.

\section{Analysis of amino acids content}

Each fermented fish sample $(2 \mathrm{~g})$ was homogenised with $15 \mathrm{~g} / 100-\mathrm{mL}$ trichloroacetic acid (TCA) (Sigma Chemical Co., St. Louis, MO, USA) and diluted to $15 \mathrm{~mL}$ and incubated for $2 \mathrm{~h}$. The mixture was centrifuged at 10,000 rpm for $15 \mathrm{~min}$. After centrifugation, $5 \mathrm{~mL}$ of supernatant was removed to a new centrifuge tube, and the $\mathrm{pH}$ value was adjusted to 2.0 with $3 \mathrm{~mol} / \mathrm{L} \mathrm{NaOH}$ solution. The volume was then adjusted to $10 \mathrm{~mL}$ and the tube was shaken well. After filteration $(0.22 \mu \mathrm{m}), 400 \mu \mathrm{L}$ of each sample was added into liquid phase vials (Sigma Chemical Co.). Finally, the content of amino acids was determined by the automatic amino acids analyzer. Each group was measured thrice in parallel.

\section{Analysis of volatile compounds}

The analysis of volatile compounds was conducted by employing the solid-phase microextraction (SPME) 
combined with gas chromatography-mass spectrometry (GC-MS; GC6890-MS5975, Agilent Technologies, USA) on AHP-5MS column $(30 \mathrm{~m} \times 0.25 \mathrm{~mm} \times$ $0.25-\mu \mathrm{m}$ film thickness, Agilent Technologies) plus detection conditions with some modifications. Meat sample, $5 \mathrm{~g}$, and $5-\mu \mathrm{L} 0.18-\mathrm{g} / \mathrm{mL} \mathrm{NaCl}$ were placed into a $15-\mathrm{mL}$ headspace vial (Sigma Chemical Co.). Then the SPME fibre $(65-\mu \mathrm{m}$ PDMS/DVB, Supelco, USA) was put in the headspace of the sample vial at $60^{\circ} \mathrm{C}$ for $40 \mathrm{~min}$. After extraction, the SPME fibre was immediately inserted into the GC-MS injector port at $250^{\circ} \mathrm{C}$ for $5 \mathrm{~min}$.

Samples were analysed using the GC-MS software (TSQ Quantum XLS, Thermo Fisher Scientific, Waltham, MA, USA). The oven temperature was maintained at $40^{\circ} \mathrm{C}$ for $2 \mathrm{~min}$, increased to $160^{\circ} \mathrm{C}$ at a rate of $4{ }^{\circ} \mathrm{C} / \mathrm{min}$, and further to $250^{\circ} \mathrm{C}$ at a rate of $10^{\circ} \mathrm{C} /$ min, for $5 \mathrm{~min}$. The inlet temperature was $250^{\circ} \mathrm{C}$ and the ionization energy was $70 \mathrm{eV}$. The temperature of the ion source was $230^{\circ} \mathrm{C}$, with a corresponding interface temperature of $280^{\circ} \mathrm{C}$ and a detector temperature of $150^{\circ} \mathrm{C}$. The model was put on full scanning, and the mass range was 35-350 atomic mass unit (amu). The data analysis was performed using GC-MS (TSQ Quantum XLS) software. Tentative identification of volatile compounds was determined by comparing mass spectra using NIST2005 and Wiley 7 databases (Hewlett-Packard, Palo Alto, CA, USA) and previously reported retention indices (RI). The retention indices of compounds were calculated after injection of an $n$-alkane series (C7-C26) with the same operating conditions. The 2,4,6-trimethylpyridine $(0.5 \mathrm{~mL}, 100 \mathrm{ppm})$ was used as an internal standard, and the relative concentration of volatile compounds in the samples was calculated by comparing the peak area of each compound with that of internal standard, assuming equal responses for all compounds.

\section{Data analysis}

O2PLS was employed to reveal the relationship between bacteria at the genus level and different flavour components using SIMCA 14 (demo v.1.0.1) (Umetrics AB, Umeå, Sweden). It was carried out by integration of bacterial taxa (defined as X matrix) and flavours (defined as Y matrix) (Bylesjö et al., 2007), which was evaluated by seven-fold cross-validation (Trygg, 2002). Terms with larger variable importance (VIP) value $(>1)$ were most relevant for explaining Y variable. VIP $(>1)$ and correlation matrix $(|\rho|>0.8)$ were used to determine potential functional bacterial in fermented fish using the Microsoft ${ }^{\circ}$ Excel, R software (v.2.14.1) and Cytoscape (v.2.8.3). PCA and hierarchical cluster analysis (HCA) were performed in SIMCA 14 software.

\section{Results and Discussion}

\section{Changes and composition of bacterial communities at different stages of fermentation}

We obtained 975,723 high-quality V4-V5 (16S) sequences from 21 fermented fish samples. The number of OTUs was 1,064 at CX stage, which dropped sharply to 356 at the end of fermentation. The diversity of bacteria (Chao 1 index) was highest in the CX sample. The Shannon and Simpson indices described the species number and distribution evenness respectively (Soto et al., 2017). The fresh fish sample exhibited the highest bacterial richness. The likely reason is that the fish originated from a cultivating environment that had a high bacterial richness. As fermentation progressed, the bacterial diversity in samples tended to decrease, while bacterial richness was reduced starting from the 10th day of fermentation. It was probably that exogenous microorganisms were unable to adapt to the fermentation environment having a relatively high salt content and low $\mathrm{pH}$ (Ma et al., 2016). Good's coverage corresponds to the sampling completeness; values $>99 \%$ indicate that a sufficient bacterial diversity was captured by the sampling regime.

On the basis of OTUs categorised at the genus level, Staphylococcus was the most prominent bacterial genus $(20.76 \%)$ at the CX stage, although its abundance decreased during subsequent stages. This was likely due to its poor acid tolerance, but some studies had reported presence of Staphylococcus in fermented seafood (Zhang et al., 2015). As fermentation continued, the most abundant genera were Lactococcus, Lactobacillus, Leuconostoc, Enterococcus, and a few others. Lactococcus was the most dominant genus from CTC to CTF stages, which suggested its central role in the fermentation process. A similar observation was made by Zang et al. (2018). Lactobacillus and Leuconostoc were first observed at the CX stage; then their abundance increased with the progress of fermentation. The increased amount of metabolites of probiotic Leuconostoc and Lactobacillus could have influenced the growth of other bacteria (RuizMoyano et al., 2011). Enterococcus was found at the CTB stage and its abundance decreased with the fermentation process.

On the basis of dynamic changes that took place in bacterial community during the fermentation process, we divided the stages of fermentation into two parts: stage 1, comprising the first three experimental stages: CTX, CTA, and CTB; and stage 2, comprising the latter four experimental stages: CTC, CTD, CTE, and CTF. The bacterial profile similarity was evaluated using the distance between the sample points of PCA diagram. We observed that the same stage samples clustered together. 
In the first direction (PC1), differences between different stages of fermentation were more obvious, accounting for $84.9 \%$ of variability (Figure 1). Previous studies have reported that the bacterial community was slightly different during the acetic acid fermentation stage (Nie et al., 2017).

\section{Analysis of flavour compounds in fermented fish}

During fermentation, 124 flavour-associated compounds were detected, which included 17 FAAs and 107 volatile flavours (VFs). The total content of FAAs was less than 50 $\mathrm{mg} / 100 \mathrm{~g}$ at the CX stage; then it increased, peaked at the CTC stage, and finally it decreased to $1,525.92 \mathrm{mg} / 100$ $\mathrm{g}$ at CTF stage (50th day) (Table 1). Concentrations of aspartic acid (Asp), glycine (Gly), methionine (Met), leucine (Leu), and phenylalanine (Phe) exhibited trends comparable to that of the total FAAs. The content of total FAAs reached the maximum value between 40th and 50th day, but concentrations of lysine (Lys), histidine (His) and proline (Pro) reached the highest levels on 20th day (Table 1). The volatile flavours were divided into eight categories: 29 alcohols, 7 acids, 13 esters, 11 ketones, 20 aldehydes, 17 alkanes, 6 aromatics, and 4 others.

Considering the role of amino acids in development of flavours, it is important to determine their release during meat fermentation (Beriain et al., 2000). In our study, the content of free amino acids in fermented samples was higher than in fresh samples. Quijada et al. (2017) reported that Lactobacillus produces organic acids that could be metabolised into amino acids, and Lactobacillus is abundantly found in fermented than in fresh samples.

The volatile flavour compounds increased during ripening, which indicated that microbial activity in fermented fish samples was higher than in fresh samples. Multiple studies have observed increased content of FAAs in fermented foods (Bolumar et al., 2001; Casaburi et al., 2007; Yin et al., 2002a, 2012b). FAAs are closely related to the development of flavour in fermented products (Benito et al., 2005). Kuda et al. (2009) found that main amino acids in aji-no-susu (a traditional fermented fish with rice produced in the Noto Peninsula, Japan) were Leu, glutamic acid (Glu), alanine (Ala), Lys, and threonine (Thr). Therefore, FAAs promote the development of specific flavour components in fermented fish.

As fermentation progressed, the total content of volatile components increased gradually: the number of volatile components ranged from 38 at the $\mathrm{CX}$ stage to 84 at the CTF stage. The PCA of volatile flavours indicated that the samples were in the same cluster at the initial stages (days 0 to 20), whereas the later stages have samples of the same cluster (days 25 to 35 ).

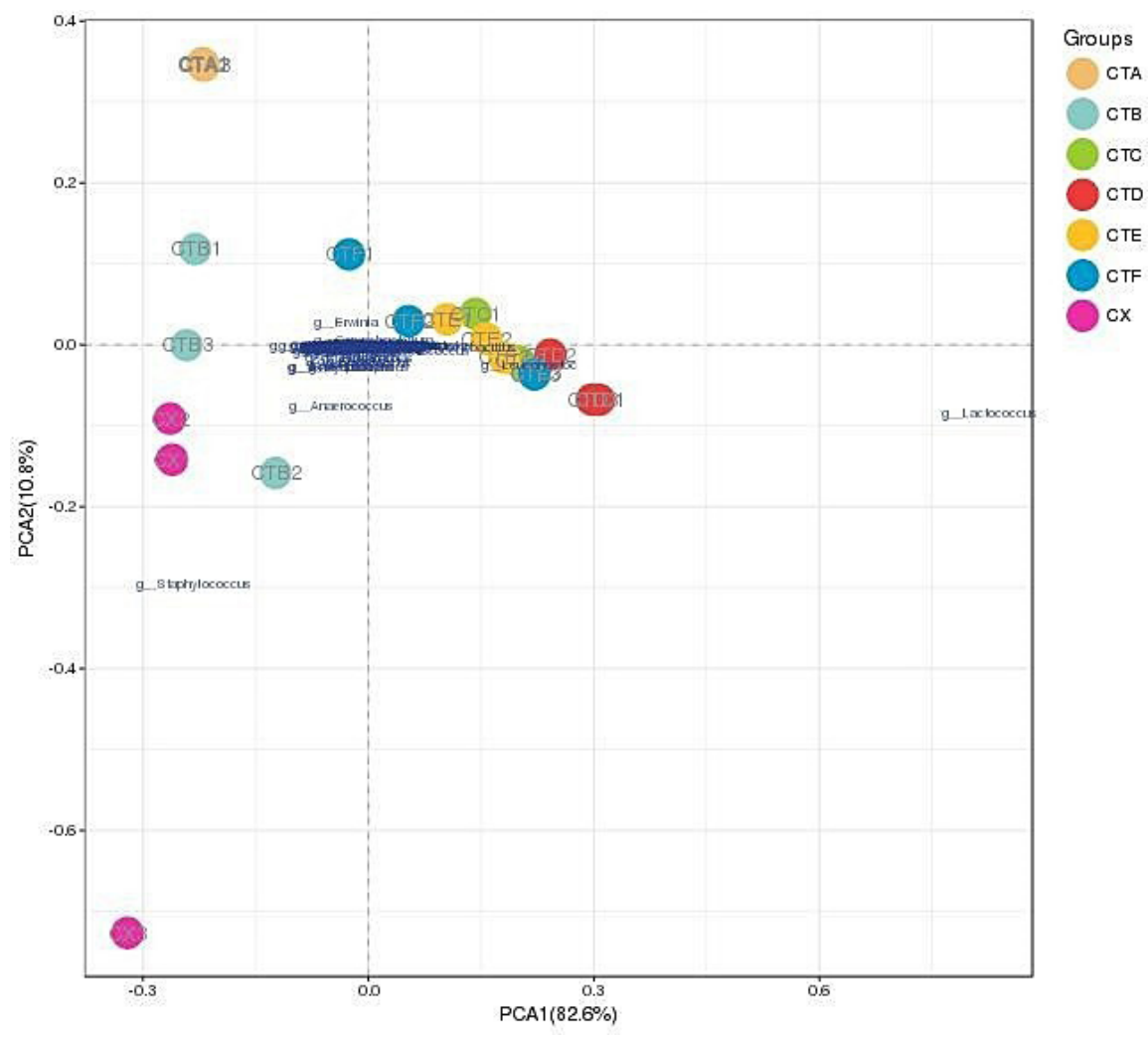

Figure 1. Comparison of bacterial succession among different stages of the fermentation process. The PCA score plot based on GC-TOFMS data set showing relationships among 21 samples. 
Table 1. The amino acid content of fermented fish at different time points.

\begin{tabular}{|c|c|c|c|c|c|c|c|}
\hline Amino acid & $\mathrm{cx}$ & CTA & СТВ & СТC & CTD & CTE & CTF \\
\hline Asp & - & $7.17 \pm 0.41^{\mathrm{a}}$ & $28.70 \pm 0.82^{b}$ & $82.54 \pm 6.77^{c}$ & $131.10 \pm 7.27^{\mathrm{e}}$ & $165.09 \pm 5.64^{f}$ & $116.59 \pm 4.12^{d}$ \\
\hline Thr & $7.64 \pm 0.48^{a}$ & $17.36 \pm 0.32^{\mathrm{a}}$ & $32.75 \pm 1.10^{b}$ & $101.35 \pm 1.42^{c}$ & $163.93 \pm 11.59^{e}$ & $147.66 \pm 1.85^{d}$ & $107.28 \pm 1.26^{c}$ \\
\hline Ser & $5.67 \pm 0.14^{\mathrm{a}}$ & $14.10 \pm 0.95^{b}$ & $17.69 \pm 0.64^{c}$ & - & - & - & - \\
\hline Glu & - & $20.78 \pm 1.43^{\mathrm{a}}$ & $79.96 \pm 2.78^{c}$ & $101.51 \pm 4.21^{d}$ & $106.85 \pm 2.99^{e}$ & $27.49 \pm 0.81^{b}$ & $28.35 \pm 0.18^{b}$ \\
\hline Gly & $6.34 \pm 0.11^{\mathrm{a}}$ & $16.26 \pm 1.01^{b}$ & $20.13 \pm 0.67^{b}$ & $51.23 \pm 1.54^{c}$ & $93.33 \pm 5.74^{d}$ & $122.50 \pm 1.13^{\mathrm{e}}$ & $121.74 \pm 0.58^{\mathrm{e}}$ \\
\hline Ala & $11.77 \pm 0.62^{\mathrm{a}}$ & $21.52 \pm 0.94^{a}$ & $54.12 \pm 1.23^{b}$ & $118.19 \pm 9.31^{c}$ & $213.41 \pm 14.18^{d}$ & $214.17 \pm 5.36^{\mathrm{e}}$ & $361.29 \pm 4.13^{f}$ \\
\hline Cys & - & $4.99 \pm 0.16^{\mathrm{a}}$ & $14.78 \pm 0.36^{\mathbf{b}}$ & $29.10 \pm 1.07^{c}$ & $61.83 \pm 2.29^{d}$ & $129.89 \pm 1.40^{f}$ & $171.89 \pm 5.27^{f}$ \\
\hline Val & - & $8.71 \pm 0.53^{\mathrm{a}}$ & $28.33 \pm 1.19^{b}$ & $56.76 \pm 1.59^{c}$ & $101.34 \pm 3.81^{d}$ & $186.13 \pm 9.16^{\mathrm{e}}$ & $216.51 \pm 0.61^{f}$ \\
\hline Met & - & $7.25 \pm 0.22^{\mathrm{a}}$ & $20.32 \pm 0.78^{b}$ & $41.67 \pm 1.24^{c}$ & $69.12 \pm 1.39^{d}$ & $86.46 \pm 0.64^{f}$ & $82.68 \pm 0.39^{f}$ \\
\hline Ile & - & $7.41 \pm 0.29^{\mathrm{a}}$ & $19.18 \pm 0.57^{b}$ & $41.88 \pm 2.60^{c}$ & $72.83 \pm 3.74^{d}$ & $113.17 \pm 1.38^{f}$ & $118.34 \pm 1.07^{f}$ \\
\hline Leu & - & $12.49 \pm 0.14^{a}$ & $51.74 \pm 2.03^{b}$ & $122.88 \pm 9.97^{c}$ & $224.25 \pm 15.78^{d}$ & $295.65 \pm 11.42^{f}$ & $284.50 \pm 1.56^{f}$ \\
\hline Tyr & - & $10.18 \pm 1.82^{\mathrm{a}}$ & - & - & - & - & - \\
\hline Phe & $6.59 \pm 0.08^{\mathrm{a}}$ & $18.36 \pm 0.93^{b}$ & $18.94 \pm 0.27^{b}$ & $41.91 \pm 1.97^{c}$ & $105.23 \pm 1.93^{d}$ & $129.53 \pm 3.96^{f}$ & $123.70 \pm 1.34^{f}$ \\
\hline Lys & - & $18.55 \pm 0.38^{a}$ & $74.09 \pm 3.12^{c}$ & $186.17 \pm 20.21^{d}$ & $44.02 \pm 1.17^{b}$ & $16.86 \pm 0.53^{a}$ & $6.39 \pm 0.17^{\mathrm{a}}$ \\
\hline His & $7.11 \pm 0.44^{\mathrm{a}}$ & $33.32 \pm 1.42^{b}$ & $60.64 \pm 0.97^{c}$ & $91.76 \pm 1.18^{f}$ & $83.06 \pm 2.54^{f}$ & $64.88 \pm 0.54^{d}$ & $64.52 \pm 0.04^{d}$ \\
\hline Arg & - & $18.08 \pm 17.21^{a}$ & - & - & - & - & - \\
\hline Pro & $2.53 \pm 0.10^{\mathrm{a}}$ & $9.84 \pm 0.62^{d}$ & $18.01 \pm 0.60^{f}$ & $24.17 \pm 1.50^{g}$ & $4.76 \pm 0.38^{b}$ & $12.42 \pm 0.61^{f}$ & $6.64 \pm 0.21^{c}$ \\
\hline Total & 47.65 & 246.37 & 539.38 & 1091.12 & 1475.06 & 1711.9 & 1525.92 \\
\hline
\end{tabular}

Note: Mean values with different superscript letters within the same row indicate a significant difference at $P<0.05$.

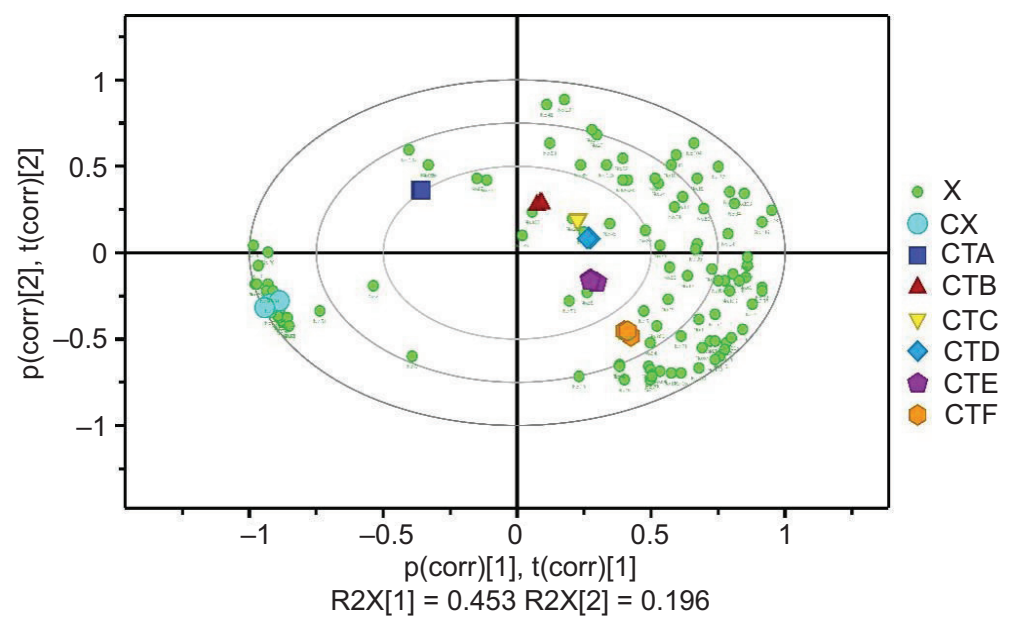

Figure 2. (A) PCA analysis of flavours during the fermentation process. (B) The biplot superimposed the scores and loadings of PCA analysis based on the correlation scaling method. R2VX represents the fraction of $X$ variation modelled in the component. $\mathrm{p}$ (corr) and $\mathrm{t}$ (corr) is a combined vector, $\mathrm{p}$ (corr) represents loading $\mathrm{p}$ scaled as a correlation coefficient between $\mathrm{X}$ and $\mathrm{t}$; $\mathrm{t}$ (corr) represents score $t$ scaled as a correlation coefficient resulting in all points falling inside the circle with radius 1.

Figure 2 establishes that the contents and categories of volatile flavour compounds increased during the fermentation process. The biplot of O2PLS in Figure 2 reveals detailed characteristics of volatile flavour compounds at different time points during fermentation. Scores and loadings suggest that hexadecane, acetophenone and heptanal were highly correlated at CX stage; octadecane, serine (Ser) and arginine (Arg) were highly correlated at CTA stage; camphor and styrene were highly correlated at CTB stage; cedrol was highly correlated at CTC stage; 
7-hexadecenal and octanoic acid were highly correlated at CTD stage; propanoic acid and 2-heptanone were highly correlated at CTE stage; and 3-pentanol, acetic acid, hexanoic acid, and Asp were highly correlated at CTF stage.

\section{Correlation between bacteria and flavours during the fermentation process}

The relationship between bacteria and flavours during the fermentation process was analyzed by the O2PLS method: R2 and Q2 values of the model were 0.978 and 0.521 , respectively (Table 2). When $\mathrm{R} 2$ and $\mathrm{Q} 2$ values were $>0.5$, the model is considered good (Dong et al., 2015); therefore, these results suggest that the O2PLS method fitted well for analysis. The first two predictive components were significant at cross-validation, accounting for $97.8 \%$ of R2 (cum) and $93.4 \%$ of Q2 (cum) of this model. The VIP (pred) vector suggested that a total of 107 bacterial genera (VIP > 1) (Figure 3A) had important effects on flavours.

Rummeliibacillus, Ralstonia and Pseudoxanthomonas were the major bacterial taxa associated with the generation of flavours during fermentation. Based on the correlation coefficient between flavours and microbiota, a total of 59 bacterial genera were highly correlated $(|\rho|>0.8)$ with two flavour sets, among which a total of 27 bacteria were correlated with volatile flavours (light red circles on the right side of Figure 3B), and 22 bacteria were correlated with amino acids (light green circles on the right side of Figure 3B). Lactobacillus and Veillonella had the maximum number of strongly correlated flavours (19 and 13, respectively) $(|\rho|>0.8)$. As for amino acids, Ala, Leu and valine (Val) were major contributors to the flavour of fermented fish. Leu, which provides umami taste to fermented fish, was correlated with three genera $(|\rho|>0.8)$. Ala, which provides sweet taste to fermented fish, was also highly correlated with three bacterial genera $(|\rho|>0.8)$. Val, which provides sweet and bitter taste to fermented fish, was highly correlated with two bacterial genera $(|\rho|>0.8)$.

A total of 27 genera were correlated with 45 volatile flavours $(|\rho|>0.8)$, among which Psychrobacter, Lactobacillus, Rhodococcus and Corynebacterium were correlated with 11, 9, 9 and 7 volatile flavours $(|\rho|>0.8)$, respectively. Lactobacillus was positively correlated with most of the flavours; its correlation coefficients with

Table 2. Model parameters

\begin{tabular}{llllll} 
Model & Type & A & N & $\begin{array}{c}\text { R2X } \\
\text { (cum) }\end{array}$ & $\begin{array}{c}\text { Q2 } \\
\text { (cum) }\end{array}$ \\
\hline M1 & PCA-X & 6 & 21 & 0.978 & 0.521 \\
\hline
\end{tabular}

phenylethyl alcohol, decanoic acid, ethyl ester, hexadecanoic acid, ethyl ester, and methyl salicylate were $>0.9$. Some bacterial genera were also negatively correlated with some flavours; for example, the correlation coefficient between Lactobacillus and 1-Penten-3-ol was -0.8, and both Psychrobacter and Rhodococcus were negatively correlated with most of the flavours (Figure 3B).

Few studies have examined the relationship between bacteria and flavours in traditional fermented foods (Carpino et al., 2017). In our study, the O2PLS method was merged with linear regression analysis to combine bacterial and flavour dataset to determine relationship between bacteria and flavours in the fermentation process. A total of 59 bacterial genera were strongly correlated with most fermented fish flavours across all seven time points, suggesting that bacteria could be the main producer of flavours.

For example, Lactobacillus, Leuconostoc and Lactococcus had a strong positive correlation with 29 flavours, whereas Pseudomonas and Erwinia had a significant positive correlation with 15 flavours during fish fermentation. These bacteria may contribute to the formation of flavours, but this could be a new topic that needs to be studied in the future. Interestingly, we found that Lactobacillus was the most prominent bacteria across all seven time points. This genus partakes in the formation of acetic acid, but it is rarely a dominant bacterial strain (Aldrete-Tapia et al., 2014; Escobar-Zepeda et al., 2016). This indicates that fermented fish is rather unique in the aspect of composition of bacterial community. Regarding the functional relationship between bacterial community and flavour components, the bacteria and flavour depicted a very high correlation. Lactobacillus was the main factor to promote the formation of flavour. It has been reported that Lactobacillus, yeasts, and Staphylococcus are the main microorganisms associated with the fermentation and ripening of meat products (Ojha et al., 2015). Lactobacillus promotes the formation of acids and plays an important role in the fermentation process (Ozogul et al., 2017). The rapid growth of Lactobacillus could inhibit the growth of other microorganisms, thereby ensuring the safety of fermented meat products (Ojha et al., 2015). Staphylococcus is often used as a starter and added to fermented meat products together with Lactobacillus (Martin et al., 2007; Ojha et al., 2015). Esters, alcohols, acids, aldehydes, and ketones contribute to the unique flavours of fermented fish (Gao et al., 2016a; Zeng et al., 2016). The results of this study indicate that there is a high correlation between bacteria and flavour, which is similar to the results of the study conducted by Zheng et al. (2018).

However, some questions remain unresolved. Firstly, because a wide variety of bacteria produce flavour 

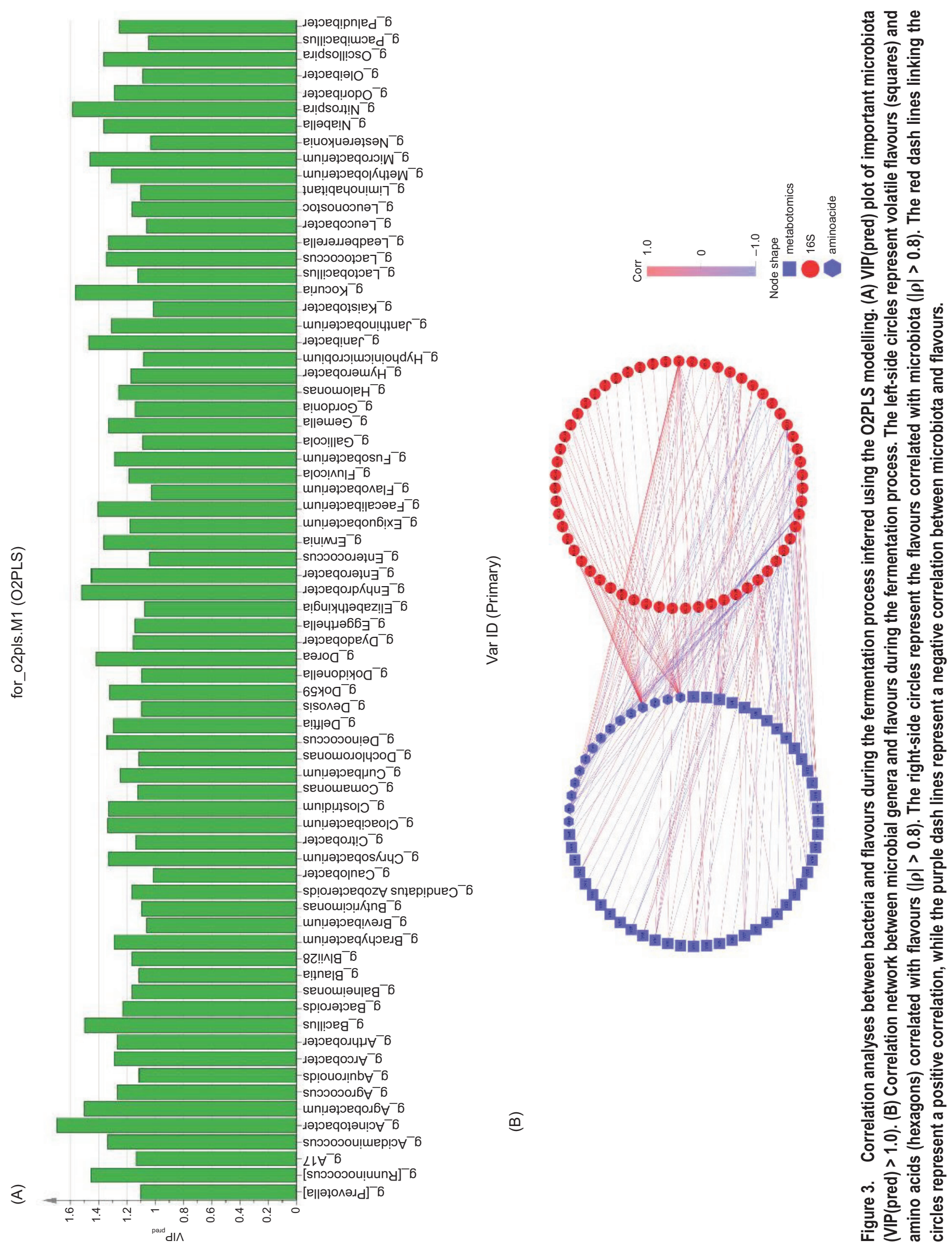
components through highly interconnected metabolic pathways, it was difficult to determine the flavour components that were produced by certain group of bacteria based on the current data. Secondly, the composition of fungal colonies must also be considered.

\section{Conclusions and Prospects}

During fermentation, a significantly positive correlation was established between Lactobacillus and Psychrobacter, which were dominant bacteria. However, Pseudomonas had a significantly negative correlation with various flavours. Therefore, different bacteria contribute to different flavours during different stages of fermentation. This implies that the quality of fermented fish is dependent on how well-balanced are the bacteria. The exploration of bacterial dynamics during fish fermentation provides valuable information for understanding the complete ecology of fish fermentation systems and provides guidelines for quality control.

This was the first study on the bacterial and flavour dynamics of fermented fish. Hence, the future studies on relationships among bacterial communities and metabolites could lead to a better understanding of the fish fermentation mechanics, thereby ensuring high-quality and production safety of fermented fish. However, the mechanism of microflora-driven flavour production during the fermentation of fish also needs to be explored in the future.

\section{References}

Aldrete-Tapia, A, Escobar-Ramírez, M.C., Tamplin, M.L. and Hernández-Iturriaga, M., 2014. High-throughput sequencing of microbial communities in Poro cheese, an artisanal Mexican cheese. Food Microbiology 44: 136-141. https://doi. org/10.1016/j.fm.2014.05.022

Benito, M.J., Rodriguez, M., Cordoba, M.G., Andrade, M.J. and Cordoba, J.J., 2005. Effect of the fungal protease EPg222 on proteolysis and texture in the dry fermented sausage 'salchichón'. Journal of the Science of Food and Agriculture 85: 273-280. https://doi.org/10.1002/jsfa.1951

Beriain, M., Horcada, A., Purroy, A., Lizaso, G., Chasco, J. and Mendizabal, J., 2000. Characteristics of lacha and rasa aragonesa lambs slaughtered at three live weights. Journal of Animal Science 78: 3070-3077. https://doi.org/10.2527/2000.78123070x

Bolumar, T., Nieto, P., Flores, J., 2001. Acidity, Proteolysis and lipolysis changes in rapid-cured fermented sausage dried at different temperatures. Food Science and Technology International 7: 269-276. https://doi.org/10.1177/108201301772660240

Bylesjö, M., Eriksson, D., Kusano, M., Moritz, T. and Trygg, J., 2007. Data integration in plant biology: the O2PLS method for combined modeling of transcript and metabolite data. Plant Journal 52: 1181-1191. https://doi. org/10.1111/j.1365-313X.2007.03293.x

Carpino, S., Randazzo, C.L., Pino, A., Russo, N. and Rapisarda, T., 2017. Influence of PDO Ragusano cheese biofilm microbiota on flavour compounds formation. Food Microbiology 61: 126-135. https://doi.org/10.1016/j.fm.2016.09.006

Casaburi, A., Aristoy, M.C., Cavella, S., Di M.R., Ercolini, D., Toldra, F. and Villani, F., 2007. Biochemical and sensory characteristics of traditional fermented sausages of Vallo di Diano (Southern Italy) as affected by the use of starter cultures. Meat Science 76: 295-307. https://doi.org/10.1016/j. meatsci.2006.11.011

Dai, Z., Li, Y., Wu, J. and Zhao, Q., 2013. Diversity of lactic acid bacteria during fermentation of a traditional Chinese fish product, chouguiyu (stinky mandarin fish). Journal of Food Science 78(11): 1778-1783. https://doi.org/10.1111/1750-3841.12289

De Filippis, F., Genovese, A., Ferranti, P., Gilbert, J.A. and Ercolini, D., 2015. Metatranscriptomics reveals temperature-driven functional changes in microbiome impacting cheese maturation rate. Scientific Reports 6: 21871. https://doi.org/10.1038/srep21871

Dong, F., 2015. Serum metabolomics study of polycystic ovary syndrome based on UPLC-QTOF-MS coupled with a pattern recognition approach. Analytical and Bioanalytical Chemistry 407: 4683-4695. https://doi.org/10.1007/s00216-015-8670-x

Ercolini, D., De Filippis, F., La Storia, A. and Iacono, M., 2012. "Remake" by high-throughput sequencing of the microbiota involved in the production of water buffalo mozzarella cheese. Appl. Environ. Microbiol 78: 8142-8145. https://doi. org/10.1128/AEM.02218-12

Escobar-Zepeda, A., Sanchez-Flores, A. and Baruch, M.Q., 2016. Metagenomic analysis of a Mexican ripened cheese reveals a unique complex microbiota. Food Microbiology 57: 116-127. https://doi.org/10.1016/j.fm.2016.02.004

Gao, P., Wang, W.X., Jiang, Q.X., Xu, Y.S. and Xia, W.S., 2016a. Effect of autochthonous starter cultures on the volatile flavour compounds of Chinese traditional fermented fish (Suan yu). International Journal of Food Science and Technology 51(7): 1630-1637. https://doi.org/10.1111/ijfs.13134

Ji, C.F., Zhang J.B., Lin X.P., Han, J., Dong X.P., Yang, S., Yan, X.M. and Zhu B.W., 2017. Metaproteomic analysis of microbiota in the fermented fish, Siniperca chuatsi. LWT-Food Science and Technology 80: 479-484. https://doi.org/10.1016/j.lwt.2017. 03.022

Jung, J.Y., Lee, S.H., Lee, H.J. and Jeon, C.O., 2013. Microbial succession and metabolite changes during fermentation of saeu-jeot: traditional Korean salted seafood. Food Microbiology 34(2): 360-368. https://doi.org/10.1016/j.fm.2013.01.009

Kouakou, A.C., Guessan, K.F. and Durand, N., 2012. Molecular bacterial characterization and free amino acids composition in Ivorian traditional fermented fish produced by two methods. Fisheries Science 78: 1125-1136. https://doi.org/10.1007/ s12562-012-0526-0

Koyanagi, T., 2011. Pyrosequencing survey of the microbial diversity of 'narezushi', an archetype of modern Japanese sushi. Letters in Applied Microbiology 53: 635-640. https://doi.org/10.1111/ j.1472-765X.2011.03155.x 
Kuda, T., Tanibe, R., Mori, M., Take, H., Michihata, T., Yano, T., Takahashi, H. and Kimura, B., 2009. Microbial and chemical properties of aji-no-susu, a traditional fermented fish with rice product in the Noto Peninsula, Japan. Fisheries Science 75(6): 1499-1506. https://doi.org/10.1007/s12562-009-0175-0

Ma, J., Li, Y., Chen, H., Zeng, Z., Li, Z.-L. and Jiang, H., 2016. Synthesis of oxylipin mimics and their antifungal activity against the citrus postharvest pathogens. Molecules 21(2): 254. https:// doi.org/10.3390/molecules21020254

Martin, A., Colin, B., Aranda, E., Benito, M.J. and Cordoba, M.G., 2007. Characterization of Micrococcaceae isolated from Iberian dry-cured sausages. Meat Science 75(4): 696-708. https://doi. org/10.1016/j.meatsci.2006.10.001

Marui, J., Boulom, S. and Panthavee, W., 2014. Culture-independent analysis of the bacterial community during fermentation of pa-som, a traditional fermented fish product in Laos. Fisheries Science 80: 1109-1115. https://doi.org/10.1007/ s12562-014-0780-4

Nie, Z., Zheng, Y., Xie, S., Zhang, X., Song, J., Xia, M. and Wang, M., 2017. Unraveling the correlation between microbiota succession and metabolite changes in traditional Shanxi aged vinegar. Sci. Rep. 7: 9240. https://doi.org/10.1038/s41598-017-09850-6

Ojha, K.S., Kerry, J.P., Duffy, G., Beresford, T. and Tiwari, B.K., 2015. Technological advances for enhancing quality and safety of fermented meat products. Trends in Food Science and Technology 44(1): 105-116. https://doi.org/10.1016/j.tifs.2015.03.010

Ozogul Y, İlknur Yuvka, Ucar Y, Durmus M, Kösker AR, Öz M, Ozogul F, 2017. Evaluation of effects of nanoemulsion based on herb essential oils (rosemary, laurel, thyme and sage) on sensory, chemical and microbiological quality of rainbow trout (Oncorhynchus mykiss) fillets during ice storage,LWT - Food Science and Technology 75: 677-684. https://doi.org/10.1016/j. lwt.2016.10.009

Paludan-Müller, C., Madsen, M. and Sophanodora, P., 2002. Fermentation and microflora of plaa-som, a Thai fermented fish product prepared with different salt concentrations. International Journal of Food Microbiology 73: 61-70. https:// doi.org/10.1016/S0168-1605(01)00688-2

Pang X.N., Han B.Z. and Huang X.N., 2018. Effect of the environment microbiota on the flavour of light-flavour Baijiu during spontaneous fermentation. Scientfic Report 8: 3396. https://doi. org/10.1038/s4:1598-018-21814-y

Quijada, N.M., De Filippis, F., Sanz, J. J., García-Fernández, M.d. C., Rodríguez-Lázaro, D., Ercolini, D. and Hernández, M., 2017. High-throughput sequencing analysis reveals different lactobacillus populations that dominate during "Chorizo de León" cured meat making. Food Microbiology 70: 94-102. https://doi. org/10.1016/j.fm.2017.09.009

Riquelme, C., Câmara, S., Enes Dapkevicius, M.-N., Vinuesa, P., da Silva, C.-G., 2015. Characterization of the bacterial biodiversity in Pico cheese (an artisanal Azorean food). International Journal of Food Microbiology 192: 86-94. https://doi.org/10.1016/j. ijfoodmicro.2014.09.031

Ruiz-Moyano, S., Martin, A., Benito, M.J., Hernandez, A., Casquete, R. and de Guia Cordoba, M., 2011. Application of Lactobacillus fermentum HL57 and Pediococcus acidilactici
SP979 as potential probiotics in the manufacture of traditional Iberian dry-fermented sausages. Food Microbiology 28: 839847. https://doi.org/10.1016/j.fm.2011.01.006

Sallam, K.I., 2007. Chemical, sensory and shelf life evaluation of sliced salmon treated with salts of organic acids. Food Chemistry 101: 592-600. https://doi.org/10.1016/j.foodchem.2006.02.019

Soto Del Rio, M.L.D., Dalmasso, A., Civera, T. and Bottero, M.T., 2017. Characterization of bacterial communities of donkey milk by high-throughput sequencing. International Journal of Food Microbiology 251: 67-72. https://doi.org/10.1016/j. ijfoodmicro.2017.03.023

Stergaard, A., Embarek, P.K.B. and Yamprayoon, J., 1998. Fermentation and spoilage of som fak, a Thai low-salt fish product. Tropical Science 38: 105-112.

Takahashi H. and Kimura, B., 2010. Comparison of PCR-DGGE and PCR-SSCP analysis for bacterial flora of Japanese traditional fermented fish products, aji-narezushi and iwashi-nukazuke. Journal of the Science of Food and Agriculture 90: 1796-1801.

Trygg, J., 2002. $\mathrm{O}_{2}$-PLS for qualitative and quantitative analysis in multivariate calibration. Journal of Chemometrics 16: 283-293. https://doi.org/10.1002/cem.724

Wang, Y., 2012. Comparison of the levels of bacterial diversity in freshwater, intertidal wetland, and marine sediments by using millions of illumina tags. Applied and Environmental Microbiology 78: 8264-8271. https://doi.org/10.1128/ AEM.01821-12

Wang, Q., Garrity, G.M., Tiedje, J.M. and Cole, J.R., 2007. Naïve bayesian classifier for rapid assignment of rRNA sequences into the new bacterial taxonomy. Applied and Environmental Microbiology 73: 5261-5267. https://doi.org/10.1128/ AEM.00062-07

Wang Y., Jiang Y.T. and Cao, J.X., 2016. Study on lipolysis-oxidation and volatile flavour compounds of dry-cured goose with different curing salt content during production. Food Chemistry 190: 33-40. https://doi.org/10.1016/j.foodchem.2015.05.048

Wang, W.X., Xia,W.S. and Xu, Y.S., 2014. Research progress on quality and safety of traditional solid-state fermentation freshwater fish. Journal of Food Safety and Quality 5: 1093-1099.

Wolfe, B.E., Button, J.E., Santarelli, M. and Dutton, R.J., 2014. Cheese rind communities provide tractable systems for in situ and in vitro studies of microbial diversity. Cell 158: 422. https:// doi.org/10.1016/j.cell.2014.05.04.1

Wolfe, B.E. and Dutton, R.J., 2015. Fermented foods as experimentally tractable microbial ecosystems. Cell 161: 49. https://doi. org/10.1016/j.cell.2015.02.034

Xiong, J., 2012. Geographic distance and pH drive bacterial distribution in alkaline lake sediments across Tibetan plateau. Environmental Microbiology 14: 2457-2466. https://doi. org/10.1111/j.1462-2920.2012.02799.x

Xu, Y., Li, L., Regenstein, J.M., Gao,P., Zang, J., Xia, W., Jiang, Q., 2018. The contribution of autochthonous microflora on free fatty acids release and flavour development in low-salt fermented fish. Food Chemistry 256: 259-267. https://doi.org/10.1016/j. foodchem.2018.02.142

Yin L.J., Pan C.L. and Jiang S.T., 2002a. Effect of lactic acid bacterial fermentation on the characteristics of minced 
mackerel. Journal of Food Science 67: 786-792. https://doi. org/10.1111/j.1365-2621.2002.tb10677.x

Yin L.J., Pan C.L. and Jiang S.T., 2002b. New technology for producing paste-like fish products using lactic acid bacteria fermentation. Journal of Food Science 67: 3114-3118. https://doi. org/10.1111/j.1365-2621.2002.tb08867.x

Yu M.J., Tan H. and Ma M.H., 2017. Bacterial community diversity and quality characteristics in traditional solid-fermented fish. Food Science 38(8): 86-95 (in Chinese with English abstract).

Zang J.H., Yu D.W., Xu Y.S., Yang F., Gao P. Xia W.S. and Jiang Q.X., 2018. Dynamics and diversity of microbial community succession during fermentation of Suan yu, a Chinese traditional fermented fish, determined by high throughput sequencing. Food Research International 111: 565-573. https://doi.org/10.1016/j. foodres.2018.05.076

Zeng, X. F., Chen, X. H. and Zhang, W., 2016. Characterization of the microbial flora from Suan Yu, a Chinese traditional low-salt fermented fish. Journal of Food Processing and Preservation, 40(5): 1093-1103. https://doi.org/10.1111/jfpp.12690

Zeng, X., Xia, W., Jiang, Q. and Yang, F., 2013. Effect of autochthonous starter cultures on microbiological and physico-chemical characteristics of Suan yu, a traditional Chinese low-salt fermented fish. Food Control 33(2): 344-351. https:// doi.org/10.1016/j.foodcont.2013.03.001

Zhang H., Li Y., Xu K., Wu J. and Dai Z., 2015. Microbiological changes and biodiversity of cultivable indigenous bacteria in Sanbao larger yellow croaker (Pseudosciaena crocea), a Chinese salted and fermented seafood. Journal of Food Science 80(4): M776-M781. https://doi.org/10.1111/1750-3841.12818

Zheng X.J., Liu F. Shi X.W., Wang B., Li K.X., Li B.K. and Zhuge B., 2018 March. Dynamic correlations between microbiota succession and flavour development involved in the ripening of Kazak artisanal cheese. Food Research International 105: 733-742. https://doi.org/10.1016/j.foodres.2017.12.007 